\title{
Evaluation of Clinical Protocol to Manage Teeth Reporting with Periapical Radiolucency to Dental Hospital - A Retrospective Study
}

Research Article

\author{
Kalyani Behera A ${ }^{1}$, Iffat Nasim $^{2 *}$, Haripriya $\mathrm{S}^{3}$
}

${ }^{1}$ Saveetha Dental College and Hospitals, Saveetha Institute of Medical and Technical Sciences, Saveetha University, Chennai, India.

${ }^{2}$ Professor, Department of Conservative Dentistry and Endodontics, Saveetha Dental College and Hospitals, Saveetha Institute of Medical and Technical Sciences, Saveetha University, Chennai, India.

${ }^{3}$ Senior Lecturer, Department of Conservative Dentistry and Endodontics, Dental College and Hospitals, Saveetha Dental College and Hospitals, Saveetha Institute of Medical and Technical Sciences, Saveetha University, Chennai, India.

\section{Abstract}

The quality of the root canal treatment ensures a good outcome of endodontic treatment, when root canal fillings are performed with adequate cleaning and shaping technique and coronal restorations. Three-dimensional sealing of the root canal is essential to prevent microleakage from periapical exudate into the root canal. Inadequate seal of the root canal system can result in contamination and entry of microbes into the periapical tissues which can further lead to the development of periapical disease.Quality of the coronal restoration also play an important role in achieving an adequate seal and prevents microleakage. The current study aims at evaluating the clinical protocol to manage teeth with periapical radiolucency reporting to a dental hospital in chennai.Case records of around 86,000 patients availing treatment at our dental hospital between june 2019 and march 2020 were analyzed and the required data was extracted. A total of 482 results were extracted based on the presence of periapical lesions evaluated by viewing periapical radiographs.Data transferred to excel sheets and imported to SPSS software. Results revealed that on assessing the association between age and the periapical lesions,periapical lesion size $1-3 \mathrm{~mm}$ and $3-5 \mathrm{~mm}$ were more observed in $18-30$ years age group when compared to other age groups, but it was not statistically significant $(p>0.05)$. On assessing the association between gender and the periapical lesion, more number of periapical lesions were present in males with the lesion size of $1-3 \mathrm{~mm}$ and $3-5 \mathrm{~mm}$ when compared to females but it was not statistically significant $(\mathrm{p}>0.05)$. On comparing the association between teeth and periapical lesion, maximum number of periapical lesions was found in the upper left quadrant with the lesion size of $1-3 \mathrm{~mm}$ as compared to other teeth but it was not statistically significant $(\mathrm{p}>0.05)$. On assessing the association between cleaning and shaping technique and periapical lesions, majority of cases rotary files were used in periapical lesion size of 1-3mm and 3-5mm but it was not statistically significant $(\mathrm{p}>0.05)$. Associations between the irrigants and periapical lesions, majority of cases $\mathrm{NaOCL}$, EDTA and saline were used for irrigation in patients with periapical lesion size of $1-3 \mathrm{~mm}$ and 3-5 $\mathrm{mm}$ but it was not statistically significant $(\mathrm{p}>0.05)$. On comparing the association between obturation technique and periapical lesions, majority of cases lateral compaction was used in patients with periapical lesion size of $1-3 \mathrm{~mm}$ as compared to other techniques but it was not statistically significant $(\mathrm{p}>0.05)$ and also it was observed that on comparing the association between intracanal medicaments and periapical lesions, majority of cases calcium hydroxide was used as an intracanal medicaments in patients with periapical lesion size of $1-3 \mathrm{~mm}$ and $3-5 \mathrm{~mm}$ but it was not statistically significant $(\mathrm{p}>0.05)$

Keywords: Abscess; Cysts; Granuloma; Periapical Lesion; Periapical Radiolucency.

\section{Introduction}

The success of any endodontic treatment depends on a wide range of factors, including proper diagnosis, proper access cavity, correct determination of working length, achieving good apical sealing, preparing the root canal using hand and rotary instruments in order to obtain mechanical preparation $[1,2]$. Diagnostic aids like the pulp vitality tests are the valuable diagnostic tools that help in accurate diagnosis and appropriate treatment planning [3]. СBCT has been routinely used to achieve proper diagnosis and treatment planning [4]. Root canal treatment depends primarily

*Corresponding Author:

Iffat Nasim,

Professor, Department of Conservative Dentistry and Endodontics, Saveetha Dental College and Hospitals, Saveetha Institute of Medical and Technical Sciences, Saveetha University, Chennai, India.

Tel: +91-9940063567

E-mail: Iffatnasim@saveetha.com

Received: October 07, 2020

Accepted: November 22, 2020

Published: November 25, 2020

Citation: Kalyani Behera A, Iffat Nasim, Haripriya S. Evaluation of Clinical Protocol to Manage Teeth Reporting with Periapical Radiolucency to Dental Hospital - A Retrospective Study. Int J Dentistry Oral Sci. 2020;7(11):1067-1071. doi: http://dx.doi.org/10.19070/2377-8075-20000211

Copyright: Iffat Nasim ${ }^{\circ} 2020$. This is an open-access article distributed under the terms of the Creative Commons Attribution License, which permits unrestricted use, distribution and reproduction in any medium, provided the original author and source are credited. 
on the removal of microorganism through chemo-mechanical instrumentation. Shaping and cleaning technique of a root canal system along with the preservation of the surrounding periodontal tissues are the principal goal of an endodontic treatment [5] During endodontic treatment, root canal irrigants include the cleaning and lubrication of the root canal system by dissolution of inorganic and organic substances. The major hurdle in root canal disinfection is the removal of the bacterial biofilm that can be achieved through proper irrigation protocol and final irrigant activation and complete sealing of root canal space.Use of an effective intracanal medicament has also aided in disinfection of the root canal system, reduced inflammation and thereby reducing postoperative pain.

Inadequate seal of the root canal system can result in contamination and entry of microbes into the periapical tissues which can further lead to the development of periapical diseases. Quality of the coronal restoration also plays an important role in achieving an adequate seal and preventing coronal microleakage. Thus, root canal fillings and coronal restorations of the tooth should resume its functions within the oral cavity and the previous periapical lesions should be repaired, and this normality should be maintained for a long time. However, no endodontic treatment protocol ensures $100 \%$ clinical and radiographic success. Thus, deficient root canal instrumentation would lead to failure and continuity of periapical lesion $[6,7]$. Coronal-sealing disruption favors microbial recolonization in the root canal and leads to endodontic treatment failure [8]. The aim of this retrospective study was to evaluate clinical protocol to manage teeth with periapical lesion reporting dental hospital in chennai.

\section{Material and Methods}

The type of research was a cross sectional analytic study. All dependent variables here were mainly assessed. The data collection was retrospective in nature. Case records of around 86,000 patients availing treatment at our dental hospital between june 1 2019 to march 312020 were analyzed and the required data was extracted. Inclusion criteria included all patients aged 18 years of age and above, who presented with symptomatic or asymptomatic apical periodontitis having periapical lesions. Patients below 18 years of age, periodontal disease were excluded from the study. The data was first extracted and then all data was transferred to an MS Excel sheet and tabulated. SPSS software was used for performing statistical analysis. Chi square test was done along with other tests to determine correlation between the dependent and the independent variables. Since most of the variables were parametric in nature. Graphs and charts were obtained for all the data and analysed. Results were displayed as percentages. The ethical clearance for the study was obtained from the institutional research SDCC/SIHEC/2020/DIASDATA/0619-0320. Patient personal information was kept confidential in exception to the examiners.

\section{Result and Discussion}

In the present study, on assessing the association between age and the periapical lesions, periapical lesion size $1-3 \mathrm{~mm}$ and $3-5 \mathrm{~mm}$ were more observed in 18- 30 years age group when compared to other age groups, but it was not statistically significant $(\mathrm{p}>0.05)$ [Figure 1]. On assessing the association between gender and the periapical lesion, more number of periapical lesions were present in males with the lesion size of $1-3 \mathrm{~mm}$ and $3-5 \mathrm{~mm}$ when compared to females but it was not statistically significant $(p>0.05)$ [ Figure 2]. On comparing the association between teeth and periapical lesion, maximum number of periapical lesions was found in the upper left quadrant $(21.58 \%)$ with the lesion size of $1-3 \mathrm{~mm}$ as compared to other teeth but it was not statistically significant ( $p>0.05)$ [Figure 3]. On assessing the association between cleaning and shaping technique and periapical lesions, majority of cases rotary files were used in periapical lesion size of $1-3 \mathrm{~mm}$ and $3-5 \mathrm{~mm}$ but it was not statistically significant $(\mathrm{p}>0.05)$ [Figure 4]. Associations between the irrigants and periapical lesions, majority of cases $\mathrm{NaOCL}$, EDTA and saline were used for irrigation in patients with periapical lesion size of $1-3 \mathrm{~mm}$ and 3-5 $\mathrm{mm}$ but it was not statistically significant $(p>0.05)$ [Figure 5]. On comparing the association between obturation technique and periapical lesions, majority of cases lateral compaction was used in patients with periapical lesion size of $1-3 \mathrm{~mm}$ as compared to other techniques but it was not statistically significant $(\mathrm{p}>0.05)$ [Figure 6] and also it was observed that on comparing the association between intracanal medicaments and periapical lesions, majority of cases calcium hydroxide was used as an intracanal medicaments in patients with periapical lesion size of $1-3 \mathrm{~mm}$ and $3-5 \mathrm{~mm}$ but it was not statistically significant $(\mathrm{p}>0.05)$ [Figure 7].

The complete elimination of microbial flora from the root canal system promotes periapical healing. Periapical tissue have a rich blood supply, lymphatic drainage and number of undifferentiated mesenchymal cells which promote good healing potential through

Figure 1. Bar graph showing the association between age and the periapical lesion. $\mathrm{X}$ - axis denotes age group of the patients, Y- axis denotes the number of teeth with periapical lesion. Periapical lesion size 1-3 mm(blue),periapical lesion size3-5 mm(green) were more observed in 18-30 yrs age group when compared to other age groups, but it was not statistically significant, Chi square test, Pearson chi square value $-2.775 a \mathrm{df}-2 \mathrm{p}=.250(\mathrm{p}>0.05)$.

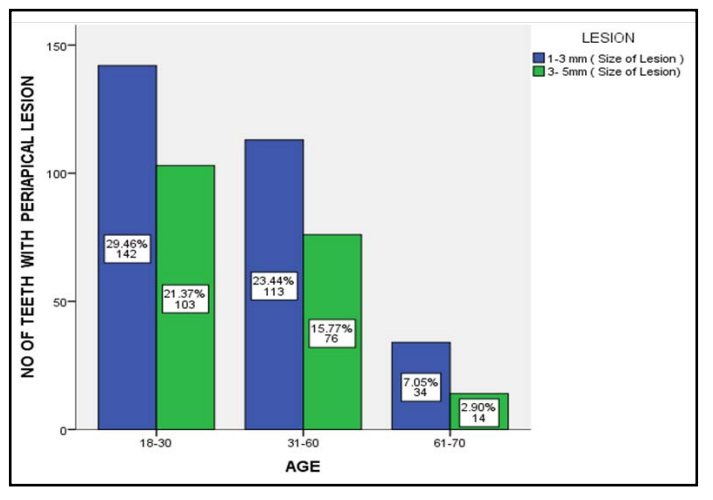


Figure 2. Bar graph showing the association between gender and the periapical lesions. $\mathrm{X}$ - axis denotes gender distribution of the patients, $Y$ - axis denotes the number of teeth with periapical lesion.More number of periapical lesions were present in males with the lesion size of $1-3 \mathrm{~mm}$ (blue) and $3-5 \mathrm{~mm}$ (green) when compared to females but it was not statistically significant, Chi square test,Pearson chi square value $-2.215 \mathrm{a} \mathrm{df}-4 \mathrm{p}=0.642(\mathrm{p}>0.05)$.

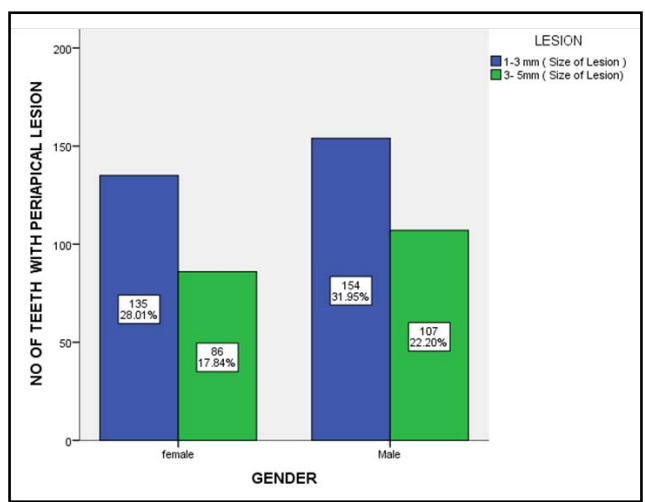

Figure 3. Bar graph showing the association between teeth and the periapical lesions. X - axis denotes teeth ( quadrant), Yaxis denotes the number of teeth with periapical lesion.Maximum number of periapical lesions was found in the upper left quadrant $(21.58 \%)$ with the lesion size of $1-3 \mathrm{~mm}$ (blue) as compared to other teeth but it was not statistically significant.Chi square test, Pearson chi square - 7.143a df- $3 \mathrm{p}=.067(\mathrm{p}>0.05)$.

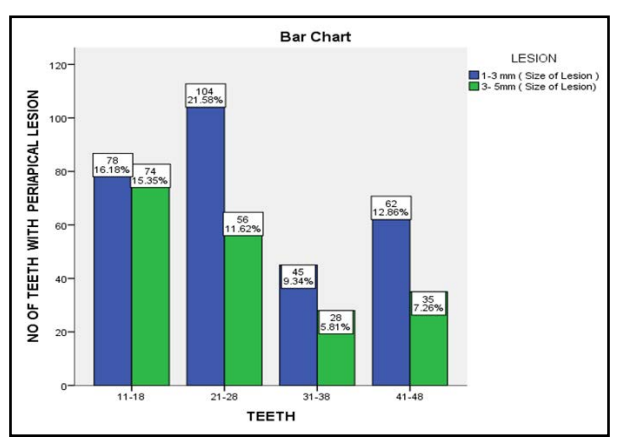

Figure 4. Bar graph showing the association between cleaning and shaping technique and the periapical lesions. $\mathrm{X}$ - axis denotes cleaning and shaping technique, $\mathrm{Y}$ - axis denotes the number of teeth with periapical lesion.In majority of cases rotary files were used in periapical lesion size of $1-3 \mathrm{~mm}$ ( blue) and 3-5mm (green) but it was not statistically significant. Chi square test, Pearson chi square value $-16.342 \mathrm{a}$ df $-4 \mathrm{p}=.568(\mathrm{p}>0.05)$.

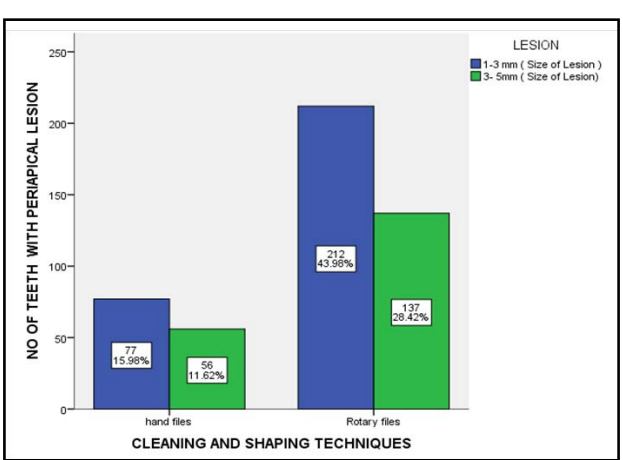

Figure 5. Bar graph showing the association between irrigants and the periapical lesions. $\mathrm{X}$ - axis denotes irrigants, $\mathrm{Y}$ - axis denotes the number of teeth with periapical lesion.In majority of cases NaOCL, EDTA and saline were used for irrigation in patients with periapical lesion size of 1-3mm( blue) 3-5 $\mathrm{mm}$ ( green) but it was not statistically significant, Chi square test, Pearson chi square value - 16.342a df- $4 \mathrm{p}=.766(\mathrm{p}>0.05)$.

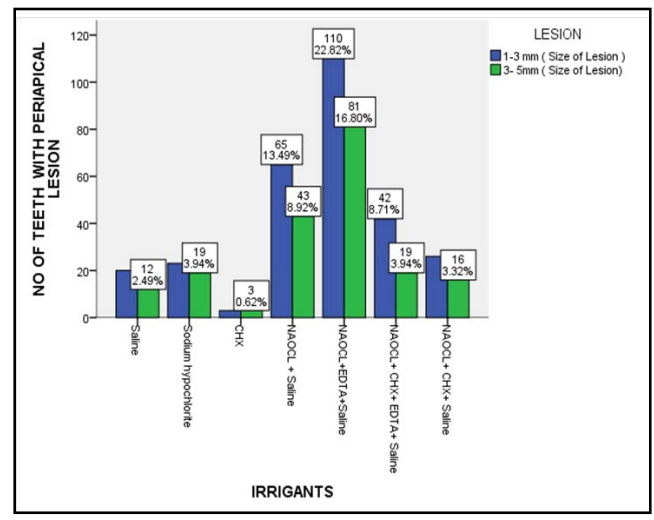


Figure 6. Bar graph showing the association between obturation technique and periapical lesion. $\mathrm{X}$ - axis denotes obturation technique, Y- axis denotes the number of teeth with periapical lesion. In majority of cases lateral compaction was used in patients with periapical lesion size of $1-3 \mathrm{~mm}$ (blue) as compared to other techniques but it was not statistically significant .Chi square test, Pearson chi square - 4.672a df- $8 \mathrm{p}=.354(\mathrm{p}>0.05)$.

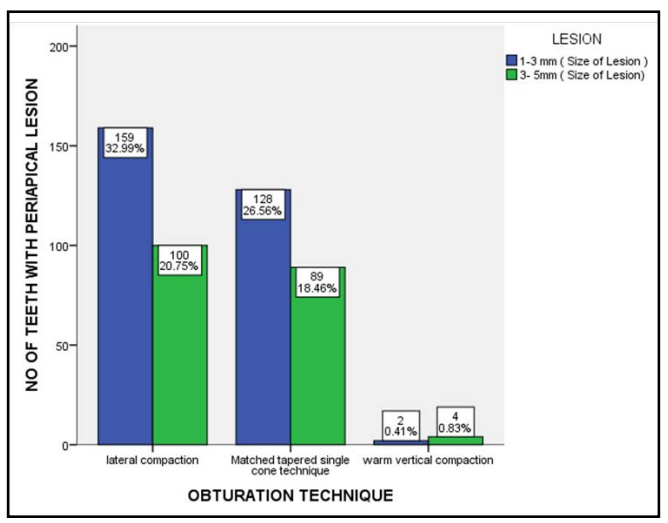

Figure 7. Bar graph showing the association between intracanal medicaments and periapical lesion. $\mathrm{X}$ - axis denotes intracanal medicaments, Y- axis denotes the number of teeth with periapical lesion. In the majority of cases calcium hydroxide was used as an intracanal medicament in patients with periapical lesion size of 1-3 mm(blue), 3-5 mm(green) but it was not statistically significant ,Chi square test. Pearson chi square - 20.648a df- $4 \mathrm{p}=.329(\mathrm{p}>0.05)$.

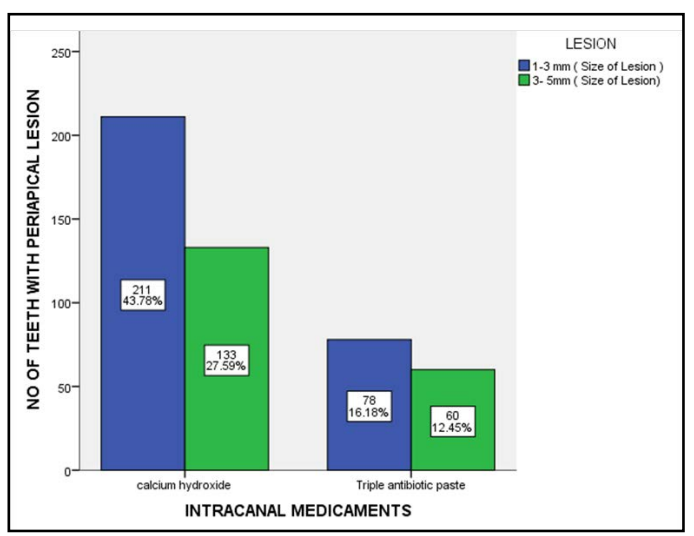

treatment procedures aiming at removal of the etiologic factors. Microbial flora plays a very important role in the development of apical periodontitis and subsequent periapical lesions [9]. Necrotic pulp provides a very good nutritional environment for the development of pathogenic bacteria which in turn multiples and release various toxins into the periapical area,thereby initiating an inflammatory reaction and development of periapical lesion. Immuno-pathologic mechanism also play a key role in the initiation of periapical lesions. During endodontic treatment, complete elimination of bacteria by instrumentation alone is impossible. Previously we have worked on Laminates and Veneers, restorative materials for cervical abrasion, management of avulsed teeth, Calcified canal and its negotiation, remineralizing agents, [10-15] In the present research we wanted to analyse factors related to management of periapical pathology. Proper irrigation and intracanal medication protocol should be followed for the complete three dimensional cleaning and disinfection of the root canal environment. Root canal instrumentation $0.5-1 \mathrm{~mm}$ short of the apex is indicated to avoid additional trauma and for reducing microbial load, meticulous debridement using irrigant such as sodium hypochlorite as an irrigant and calcium hydroxide as an intra canal medicament is essential [16-18]. The antimicrobial activity of calcium hydroxide is due to its dissociation into calcium and hydroxyl ions in a high $\mathrm{pH}$ environment which inhibits enzymatic activities such as metabolism,growth and cellular division which are essential for microbial growth. It exhibits anti-inflammatory action,anticlastic property by inhibition of phospholipase, activation of alkaline phosphatase and destruction of cystic epithelium and thus allowing connective tissue to invaginate into the lesion [19]. The antibacterial component of calcium hydroxide based root canal sealer also prevents regrowth of residual bacteria and reduce bacterial re -entry into the root canal after endodontic treatment. Clinical signs and symptoms and radiographic signs such as change in density within the lesion, trabecular reformation and lamina dura reformation should be checked during followup visits through radiographs especially in asymptomatic teeth and healthy soft tissues. Thus, complete periapical healing was observed by thorough cleaning \& shaping technique, prolonged disinfecting procedures using calcium hydroxide as an intracanal medicament and root canal sealer during obturation. Coronal restorations also play major role in maintaining integrity of tooth in the arch [20]. The result of the study showed that maxillary teeth were more involved with periapical lesion when compared to mandibular teeth. When the periapical lesions were evident, nonsurgical approach was achieved through complete cleaning and shaping technique by using rotary files with proper debridement, disinfection and three-dimensional obturation of root canal system. Healing of periapical lesion is effectively achieved through calcium hydroxide dressing as an intracanal medicament. 


\section{Conclusion}

Within the limitations of the study, it was found that patients in the age group of 18-30 years had the maximum number of periapical lesions and was more common in males. Periapical lesions were managed by using rotary files and combination of various irrigants and calcium hydroxide was the choice of intracanal medicament. Although it is necessary to observe and monitor the prognosis of periapical lesions. These protocols were followed but long term follow up is required.

\section{Acknowledgement}

The authors would like to acknowledge all the faculties of the Department of Conservative Dentistry and Endodontics for their help with data collection for this study.

\section{References}

[1]. Jose J, Subbaiyan H. Different Treatment Modalities followed by Dental Practitioners for Ellis Class 2 Fracture-A Questionnaire-based Survey. Open Dent. J. 2020 Feb 18;14(1):59-65.

[2]. Manohar MP, Sharma S. A survey of the knowledge, attitude, and awareness about the principal choice of intracanal medicaments among the general dental practitioners and nonendodontic specialists. Indian J Dent Res. 2018 Nov-Dec;29(6):716-720.Pubmed PMID: 30588997.

[3]. Janani K, Palanivelu A, Sandhya R. Diagnostic accuracy of dental pulse oximeter with customized sensor holder, thermal test and electric pulp test for the evaluation of pulp vitality: an in vivo study. Braz. Dent. Sci. 2020 Jan 31;23(1):8-p.

[4]. Ramanathan S, Solete P. Cone-beam Computed Tomography Evaluation of Root Canal Preparation using Various Rotary Instruments: An in vitro Study. J. Contemp. Dent. Pract. 2015 Nov 1;16(11):869-72.

[5]. Moreno JO, Alves FR, Gonçalves LS, Martinez AM, Rôças IN, Siqueira JF Jr. Periradicular status and quality of root canal fillings and coronal restorations in an urban Colombian population. J Endod. 2013 May;39(5):600-4. Pubmed PMID: 23611376.

[6]. Lakhanpal M, Chopra A, Gupta N, Rao NC, Vashisth S. Periapical status and quality of root canal fillings and coronal restorations in India. Universal Res J Dent. 2014;4:118-22.

[7]. Sadaf D, Alsalhy H, Alrothy R, Ahmad MZ. Prevalence of apical periodon- titis in root canal-treated teeth from an urban Saudi female population: Influence of root canal fillings and coronal restorations. Int J Oral Health Sci. 2017 Jul 1;7(2):82.

[8]. Siqueira JF Jr, Rôças IN, Alves FR, Campos LC. Periradicular status related to the quality of coronal restorations and root canal fillings in a Brazilian population. Oral Surg Oral Med Oral Pathol Oral Radiol Endod. 2005 Sep;100(3):369-74.Pubmed PMID: 16122668.

[9]. Teja KV, Ramesh S. Shape optimal and clean more. Saudi Endod. J. 2019 Sep 1;9(3):235.

[10]. Kumar D, Antony S. Calcified Canal and Negotiation-A Review. Res J Pharm Technol. 2018;11(8):3727-30.

[11]. Rajakeerthi R, Ms N. Natural Product as the Storage medium for an avulsed tooth-A Systematic Review. Cumhur. Dent. J. 2019;22(2):249-56.

[12]. Ravinthar K. Recent advancements in laminates and veneers in dentistry. Res J Pharm Technol. 2018;11(2):785-7.

[13]. Hussainy SN, Nasim I, Thomas T, Ranjan M. Clinical performance of resinmodified glass ionomer cement, flowable composite, and polyacid-modified resin composite in noncarious cervical lesions: One-year follow-up. J Conserv Dent. 2018 Sep-Oct;21(5):510-515.Pubmed PMID: 30294112.

[14]. Rajendran R, Kunjusankaran RN, Sandhya R, Anilkumar A, Santhosh R, Patil SR. Comparative Evaluation of Remineralizing Potential of a Paste Containing Bioactive Glass and a Topical Cream Containing Casein Phosphopeptide-Amorphous Calcium Phosphate: An in Vitro Study. Pesqui. Bras. Odontopediatria Clín. Integr. 2019;19:1-10.

[15]. Nandakumar M, Nasim I. Comparative evaluation of grape seed and cranberry extracts in preventing enamel erosion: An optical emission spectrometric analysis. J Conserv Dent. 2018 Sep-Oct;21(5):516-520.Pubmed PMID: 30294113.

[16]. Ramamoorthi S, Nivedhitha MS, Divyanand MJ. Comparative evaluation of postoperative pain after using endodontic needle and EndoActivator during root canal irrigation: A randomised controlled trial. Aust Endod J. 2015 Aug;41(2):78-87.Pubmed PMID: 25195661.

[17]. Noor S. Chlorhexidine: Its properties and effects. Res J Pharm Technol. 2016;9(10):1755-60.

[18]. Siddique R, Jayalakshmi S. Assessment of Precipitate Formation on Interaction of Chlorhexidine with Sodium Hypochlorite, Neem, Aloevera and Garlic: An in vitro Study. Indian J Public Health Res Dev. 2019 Nov 1;10(11):3648.

[19]. Ramesh S, Teja K, Priya V. Regulation of matrix metalloproteinase-3 gene expression in inflammation: A molecular study [Internet]. Vol. 21, Journal of Conservative Dentistry. 2018. p. 592. Available from: http://dx.doi. org/10.4103/jcd.jcd_154_18

[20]. Dammaschke T, Nykiel K, Sagheri D, Schäfer E. Influence of coronal restorations on the fracture resistance of root canal-treated premolar and molar teeth: a retrospective study. Aust Endod J. 2013 Aug;39(2):48-56.Pubmed PMID: 23890259 